\title{
Synthesis, Molecular Docking and Antimicrobial Activity of $\alpha, \beta$-Unsaturated Ketone Exchange Moiety for Chalcone and Pyrazoline Derivatives
}

\author{
Saba Farooq ${ }^{*[a]}$ and Zainab Ngaini ${ }^{[b]}$
}

Bacterial diseases cause hazardous infections due to the occurrence of bacterial resistance. Drugs production to cure bacterial resistance from natural sources has become ineffective to execute the resisted bacteria due to the unsuitable binding interaction of active sites with the receptors. Drug link to natural products moieties such as chalcones and pyrazolines, which originated from plants extracts, has become attractive among researchers due to its significant pharmaceutical moiety. In this study a series of chalcone derivatives ( $\mathbf{1} \mathbf{a}-\mathbf{d})$ has been synthesized via Claisen-Schmidt condensation, followed by cyclization to form pyrazolines $(2 a-d, 3 a-d)$. Fischer esterification of pyrazolines formed $\mathbf{4} \mathbf{a}-\mathbf{d}$ in moderate to good yield (42.91-88.23\%). Antimicrobial activities of all the synthe-

\section{Introduction}

Chalcone is a naturally derived yellowish colored pigment with significance properties in the organic synthesis and medicinal field. ${ }^{[1]}$ The color appearance in chalcone is due to the existence of unsaturated keto $(-\mathrm{C}=\mathrm{C}-\mathrm{C}=\mathrm{O})$ as a chromophore. ${ }^{[2]}$ Natural product derived molecule namely chalcone has been reported to have various biological activity i.e. antiviral, antiinflammatory, antitumor, antimicrobial, antifungal, antihyperglycemic, antidiabetic, anti HIV and antituberculosis. ${ }^{[3]}$ Based on the literature precedent, the $\alpha, \beta$-unsaturated ketone has been reported as a responsible moiety for antimicrobial activities in chalcone ${ }^{[4]}$ besides other factors such as the effect of bacterial strain, nature of bacteria, size of molecule, lipophilicity and number or position of substituents. ${ }^{[5]}$ The replacement of substituents in the molecules such as hydroxyl group to carboxyl moiety at either ring $A$ and $B$ can also increase the solubility and biological properties of chalcones. ${ }^{[6]}$ Our previous study also reported on the importance of unsaturated ketone and hydroxyl groups for excellent solubility and biological activities. ${ }^{[7,8]}$ The hydroxyl groups at ortho position and closer

[a] Dr. S. Faroog

Faculty of Resource Science and Technology, Universiti Malaysia Sarawak, 94300 Kota Samarahan, Sarawak, Malaysia

E-mail: sabafarooq61@yahoo.com

[b] Prof. Dr. Z. Ngaini

Faculty of Resource Science and Technology, Universiti Malaysia Sarawak 94300 Kota Samarahan, Sarawak, Malaysia

E-mail: nzainab@unimas.my

Supporting information for this article is available on the WWW under https://doi.org/10.1002/slct.202002278 sized compounds were evaluated against Escherichia coli and Staphylococcus aureus via disc diffusion. Among all compounds, pyrazolines $3 \mathrm{c}$ and $\mathbf{3} \mathrm{d}$ showed the highest zone of inhibition (17 $\mathrm{mm})$ compared to 1 a-d $(5-11 \mathrm{~mm})$ and standard ampicillin (11 $\mathrm{mm})$. The exchange of $\alpha, \beta$-unsaturated carbonyl showed phenomenal increment in the biological activities. Structure activity relationship of $\mathbf{1} \mathrm{a}, \mathbf{1} \mathrm{d}, \mathbf{3} \mathrm{a}$ and $\mathbf{3} \mathrm{d}$ was analyzed via molecular docking of $\mathrm{N}$-terminal domain having deoxyribonucleic acid (DNA) binding protein (4pql) with excellent binding energy of $-6.2,-6.6,-7.1$ and $-7.2 \mathrm{kcal} / \mathrm{mol}$, respectively. This work is significant in designing new drugs with keto-exchange relationship for medicinal industry.

to ketone moiety showed excellent inhibition compared to meta and para position. Nevertheless, chalcones with monosubstituents such as methoxy, nitro, $\mathrm{Cl}, \mathrm{Br}$ and ether groups, with the absence of hydroxyl groups has completely reduced the activities. ${ }^{[9]}$ The presence of electron withdrawing moieties (i.e. trifluoromethyl and halogens) with $(-\mathrm{COOH})$ chalcone, however, can potentially reduce the biological activities due to poor solubility and lipophilicity. ${ }^{[6]}$

The unsaturated $\alpha, \beta$ - keto moiety in the chalcone network is also very reactive for the formation of heterocyclic organic chalcone derivatives such as pyrimidine ${ }^{[10]}$ epoxy chalcone ${ }^{[11}$ pyrazoline. ${ }^{[12]}$ Pyrazoline is an eye catching heterocyclic molecule due to the presence of heteroatom nitrogen in cyclic ring, which played marvelous role in the field of medicines (i.e. antiepileptic, $^{[13]} \quad$ antitrypanosomal, ${ }^{[14]}$ antipyretic, ${ }^{[15,16]}$ antioxidant, ${ }^{[17]} \quad$ anti-inflammatory, ${ }^{[18]}$ antimalarial, ${ }^{[19]}$ antihistaminic ${ }^{[20]}$ ) and electronics (e.g. photographic conductor, ${ }^{[21]}$ chemo-sensor ${ }^{[22]}$ and optoelectronic $\left.{ }^{[23]}\right) .{ }^{[24]}$ Pyrazoline derivatives were commonly derived via aza-Michael addition reaction of hydrazine and chalcone derivatives under versatile conditions. ${ }^{[25]}$ Structural modifications or improvement in pyrazoline has contributed to the discovery of new drugs with less toxicity and improved potency. ${ }^{[26]}$

In chalcone derived pyrazoline, the presence of conjugated phenyl and $-\mathrm{C}=\mathrm{N}-\mathrm{NC}->$ moiety contribute to electron delocalization and resonance formation, which is significant for stability and biological activity of the molecules. ${ }^{[27]}$ Cyclization mostly enhanced the antimicrobial activities but, in some cases, can reduce the activity due to incompatibility of the molecules with the nature of bacterial strains. The presence of electron 